UPPSALA UNIVERSITET

Working Paper 2005:21

Department of Economics

\title{
Entrepreneurship and Liquidity Constraints: Evidence from Sweden
}

\author{
Jenny Nykvist
}


Department of Economics

Working paper 2005:21

Uppsala University

November 2005

P.O. Box 513

ISSN 0284-2904

SE-751 20 Uppsala

Sweden

Fax: +46184711478

\title{
ENTREPRENEURSHIP AND LIQUIDITY CONSTRAINTS: EVIDENCE FROM SWEDEN
}

\author{
JENNY NYKVIST
}

Papers in the Working Paper Series are published on internet in PDF formats.

Download from http://www.nek.uu.se or from S-WoPEC http://swopec.hhs.se/uunewp/ 


\title{
Entrepreneurship and Liquidity Constraints: Evidence from Sweden*
}

\author{
Jenny Nykvist ${ }^{\dagger}$
}

September 10, 2005

\begin{abstract}
Do potential entrepreneurs face liquidity constraints? Or to put it differently, does a person have to be wealthy to start a new business? This question has been discussed in a large literature that has documented a positive relationship between initial wealth and entrepreneurship. However, in a recent paper Hurst and Lusardi (2004) use higher order of polynomials in wealth and find that there is no relationship between household initial wealth and the probability of starting an own business throughout most of the wealth distribution in the United States. In this paper we examine this relationship using similar methods on Swedish data. The data set used is LINDA, a register-based longitudinal data set for Sweden. The relationship is estimated using probit models with different specifications of wealth. However, the result that wealth is not important for new entrepreneurs cannot be replicated. Instead, the main finding of the paper is that the relationship between wealth and transition into entrepreneurship is positive but diminishing for the major part of the wealth distribution. Moreover, the relationship between wealth and entrepreneurship gets stronger as the models get less restricted with respect to wealth. Our result leads us to the conclusion that liquidity constraints do play a significant role when determining transition into entrepreneurship in Sweden.
\end{abstract}

JEL-classification: D31, J23, J24, M13

Keywords: Liquidity constraints, wealth, entrepreneurship, starting capital, business ownership

*The work has benefitted from helpful comments from Henry Ohlsson, Eva Mörk, Henrik Jordahl, Mikael Bengtsson, Elly-Ann Johansson and seminar participants at Uppsala University. Financial support from Jan Wallander's and Tom Hedelius' Foundation is greatfully acknowledged.

${ }^{\dagger}$ Department of Economics, Uppsala University, Box 513, SE-751 20 Uppsala, Sweden, Fax: +4618-471 14 78, E-mail: jenny.nykvist@nek.uu.se. 


\section{Introduction}

One of the most frequently discussed obstacles for entrepreneurs is the inability for potential business owners to acquire necessary capital, in other words, the entrepreneurs are liquidity constrained. Liquidity constraints are in both theoretical and qualitative studies raised as a potential or actual problem (see, for example, Evans and Jovanovic 1989).

The existence of liquidity constraints and lack of capital for businesses is commonly debated in Europe. One of the most frequently discussed problem is the poorly developed venture capital market. The lack of venture capital and the gap between Europe and the United States is raised as one explanation why Europe has not had the same amount of successful entrepreneurial companies as the US and, therefore, has not experienced the same economic growth during the last decades (Bottazzi and da Rin 2003).

The role of liquidity constraints can be examined by studying the relationship between wealth and entrepreneurship on micro level data on households. If liquidity constraints are an obstacle for entrepreneurs, then low wealth households will be constrained from starting a business and we will observe a positive relationship between wealth and entrepreneurship. One advantage with investigating liquidity constraints using this approach compared to qualitative studies is that qualitative studies usually are based on either existing firms or potential firms applying for loan which will create a selection problem. This implies that by using micro level data on households we can get a better idea of the extent of the potential problem.

In empirical studies entrepreneurs are commonly defined as business owners or self-employed. Using these definitions, a large literature has documented a positive relationship between initial wealth and entrepreneurship (see, for example, Evans and Leighton 1989 and Evans and Jovanovic 1989). These results are attained by including initial wealth either linear or quadratic to the regression models as dependent variables. In a recent paper, Hurst and Lusardi (2004) includes wealth as a higher order polynomial in addition to the linear specification and find that throughout most of the wealth distribution there is no relationship between household wealth and the probability of starting an own business. From this finding they conclude that liquidity constraints do not play a crucial role when determining entrepreneurship in the United States. This view is shared by Parker (2004) who emphasizes that the previous literature has not succeeded in providing proofs that liquidity constraints exists. He argues that the positive relationship between initial wealth and entrepreneurship can reflect a number of things such as decreasing absolute risk aversion and preferences for being self-financed. In this paper we will not investigate this closer, instead, we will focus on the findings of Hurst and Lusardi (2004) and investigate whether there are liquidity constraints in Sweden.

Hurst and Lusardi (2004) argue that there are mainly two reasons for the result that wealth is not important when determining entrepreneurship in the United States. First, the capital required to start a business in the United States is low. Second, good institutions are available to provide funds for entrepreneurs. As discussed above the situation is different in Europe regarding the last point. If we look closer at Sweden we will find that Sweden is no exception from the European situation. The Swedish financial system is described as one of the most bank oriented in the world with a large business lending but firms still 
experience difficulties in finding financing in the starting up phase. As in the rest of Europe, the difficulties have been explained by the lack of venture capital in early development phases. The Swedish private equity and venture capital market has grown rapidly during the last decade and today Sweden has one of highest levels of private equity investment as a share of GDP among OECD countries. If we compare Sweden with the rest of Europe then according to EVCA (2004) Sweden had in 2003 the second highest (after United Kingdom) private equity investments in western Europe as a share of GDP. However, most of the capital is invested in late stages and the problem of finding financing in the early stages of the companies remains serious (Baygan 2003).

Based on the previous discussion we have reasons to believe that there are more severe liquidity constraints in Sweden than in the United States and furthermore that this is true for the whole western Europe. An interesting question is whether this view can be supported by micro data. Based on the presented view that European potential entrepreneurs have difficulties in finding capital in the starting up phases we would expect that the results will differ from those of Hurst and Lusardi (2004). The questions are: Will we attain the same results as Hurst and Lusardi (2004) using Swedish data? Are liquidity constraints a substantial obstacle to new entrepreneurs in Sweden?

A couple of economic papers have earlier been written on entrepreneurial activities and liquidity constraints in Sweden. For instance, Lindh and Ohlsson (1996) use Swedish data to investigate the relationship between self-employment and windfall gains. Lottery wins and inheritance are used as instruments for liquidity and they find that there are binding liquidity constraints. Lindh and Ohlsson (1998) find further support for the liquidity constraint hypothesis by investigating the relationship between wealth inequality and self-employment in time-series data. In a recent paper, Giannetti and Simonov (2004) investigate how personal and environmental characteristics can explain differences in entrepreneurial activity among Swedish municipalities. Among a lot of other things, they find that wealth increases the probability of starting a business and hence they conclude that there exists liquidity constraints. Thus, previous studies on Swedish data has agreed that there are liquidity constraints facing new entrepreneurs but the question is if this result remains when including a higher order polynomial in wealth. The purpose of this paper is to investigate this in the manner of Hurst and Lusardi (2004).

We are going to use LINDA data, which is a register based panel data set for Sweden. The database includes a lot of information about a large panel of individuals and their family members. The fact that the data set is longitudinal allows us to study the individuals transition into entrepreneurship. This is a better strategy than using only entrepreneurship due to causality problems. Thanks to the large sample size we will also be able extend the analysis by using fine definitions of wealth dummy variables. The binomial and multinomial probit model will be used to estimate the relationship in the data.

One problem associated with empirically investigating liquidity constraints is the endogenity problem. It is possible that there exists individual characteristics that make the individual more prone to accumulate wealth as well as to start a business. If we are not able to control for these traits then an estimated positive relationship between wealth and entrepreneurship could simply reflect these traits and not liquidity constraints. In an attempt to evade this problem we will, in the manner of Hurst and Lusardi (2004), divide the businesses into 
high and low starting capital businesses. If there are liquidity constraints then we would expect the relationship between wealth and entrepreneurship to be stronger for high starting capital businesses.

The paper is organized as follows. We will start with a brief account for the theoretical background and econometric problems. After this the data used in the paper will be discussed and described. In the following section the results will be presented. First, we look at the base results where we use polynomial wealth models and a wealth dummy variable model on a whole and truncated sample respectively. Second, we will investigate entrepreneurs depending on starting up costs for the business. After this we will present some robustness results and finally we conclude by summarizing and commenting the results.

\section{Method}

\subsection{Theoretical background}

Evans and Jovanovic (1989) develop a model that makes it possible to test for liquidity constraints. The main assumption of the model is that new entrepreneurs only can borrow a share $(\lambda-1)$ of their initial wealth $(z)$, where $\lambda \geq 1$. This implies that the amount borrowed cannot exceed $(\lambda-1) z$ and the most a person can invest in a business is $z+(\lambda-1) z=\lambda z$. Therefore, the constraint that a new potential entrepreneur faces is:

$$
0 \leq k \leq \lambda z
$$

where $k$ is the amount of capital invested in the business. The model is static and the entrepreneur's earnings depend on $k$ via the production function $y=\theta k^{\alpha} \varepsilon$, where $\theta$ is entrepreneurial ability, $\varepsilon$ is a lognormal disturbance and $\alpha \in$ $(0,1)$. Following (Lucas 1978), a constrained borrower enters entrepreneurship if the expected earnings net of capital costs from doing so exceeds that from paid employment, $w$. This occurs iff:

$$
\theta(\lambda z)^{\alpha}-(1+r) \lambda z>w
$$

where $r>0$ is the nominal interest rate. If the left hand side of (1) is differentiated then we can verify that the probability to enter entrepreneurship is an increasing function of initial wealth if the potential entrepreneur is constrained. It can be shown that for an unconstrained borrower there is no relationship between initial wealth and entrepreneurship. Thus, if initial wealth is exogenous and positively correlated with entrepreneurship then this implies that potential entrepreneurs face liquidity constraints.

The theoretical model provides us with a tool to test for liquidity constraints by simply running a regression on entrepreneurship and initial wealth. However, for this approach to be valid wealth must be exogenous. We have reasons to believe that wealth as a matter of fact may not be exogenous. The next section discuss the problem and how it will be handled in the empirical analysis. 


\subsection{The endogenity problem}

The endogenity problem arises for two reasons. The first reason is that the individuals can have accumulated wealth as entrepreneurs, that is entrepreneurship leads to wealth and not the other way around. To mitigate this causality problem several articles have suggested that one should use transition into entrepreneurship instead of being entrepreneur as dependent variable. Hence, in the paper the dependent variable will be transition into entrepreneurship and by using this specification the endogenity problem arising for this reason is handled.

The second reason is that there may exist traits that makes some individuals more prone to accumulate wealth as well as to start a business. This could, for example, be lower levels of risk aversion and higher financial sophistication or other unmeasured and unknown traits that makes the individual more prone to both become an entrepreneur and accumulate wealth. The entrepreneurial ability or traits are typically hard to control for and this creates a potential omitted variable bias. If wealth is positively correlated with entrepreneurial ability and this ability is positively correlated with entrepreneurship, then wealth will capture the effect of not only wealth but also of entrepreneurial ability. This implies a potential positive bias for the wealth-regressor and hence the role of liquidity constraints will be exaggerated. Moreover, the use of the non-linear probit model implies that all marginal effects will possibly be biased. Because the endogenity problem causes counteracting biases in the marginal effects we do not now in which direction this potential bias goes.

In the base regressions the endogenity problem will to some extent be handled by including the variable former entrepreneur which is discussed closer in the following section. The endogenity problem will also be handled by using an additional method that simply evades the problem. As discussed in the introduction the entrepreneurs will be divided into two groups depending on whether they have started a high or low starting capital business and then the relationship with wealth for the two groups of entrepreneurs will be compared. If there exist liquidity constraints we would expect the entrepreneurs who starts a high starting capital business to experience more extensive liquidity constraints than those entrepreneurs who start low starting capital business. This implies that the relationship between wealth and transition into entrepreneurship should be stronger for high starting capital entrepreneurs if there exists liquidity constraints.

\section{Data}

We are going to use LINDA, which is a longitudinal register-based data set for Sweden. The data set includes some 300,000 individuals and their household members and is cross-section representative. It has information about personal and demographic characteristics, employment and occupational status, sources and amount of income and wealth. Detailed information about the individual and household wealth is available from 1999, before this we only have information about the total taxable wealth (more than SEK 800,000 or 900,000). The latest available data is from 2002 and therefore the main sample is limited to include observations from 1999 to 2001. The data from 2002 is used to create the dependent variable (transition into entrepreneurship) for 2001. 
The sample will be restricted to only include sample individuals in the ages 18-60. This is to avoid the largest part of the individuals who are still in elementary school and those who are close to retirement or retired. ${ }^{1}$

\subsection{Dependent variable}

LINDA provides information on whether the individual has reported to the tax authority that he/she has received any capital income from an individual firm, unlimited partnership or economic association that he/she owns. It also includes information about whether these individuals are active or passive business owners. Income from an active business is defined as income received from an own firm in which the individual works at least 33 percent out of full time and controls.

Moreover, the data set includes information on whether the individual is an owner of a limited company with four or less owners that control the business i.e. they own together stocks that correspond to more than 50 percent of the votes (fämansföretag). ${ }^{2}$ To be regarded as an owner of this kind of limited companies the individual needs not be active or work within the business. Companies quoted on the exchange are an exception and are not regarded as this kind of limited company. The data also includes information on whether the owner has declared any labor income from the company. If the labor income received from the company exceeds other labor income the individual is in this paper regarded as an active owner.

Entrepreneurs can be defined in several different ways using the data. The specification of dependent variable is important and can possibly affect the results. Two possible approaches are to either chose all business owners or only the active business owners (self-employed). It is not clear cut which definition to use. One can argue that all business owners will be restricted if there are liquidity constraints and, hence, one should use the broader definition. However, the maybe most interesting relationship is for those individuals who are selfemployed. One shortcoming with the second definition is that the limit between passive and active business ownership for limited companies can be argued to be somewhat arbitrary. Hence, in the main part of the paper the broader definition of entrepreneurs will be used but as a robustness check we will use self-employment. To clarify, we define business owner as an individual who has received any capital income (negative or positive) during the last year from passive or active business or are owners of an limited company (fåmansföretag) and self-employed as individuals who have received capital income from an active business or labor income from an limited company (fåmansföretag) that exceeds labor income received from other employers .

The share of business owners in the sample is approximately 13.7 percent and for self-employed it is 7.2 percent. According to the Swedish labor force survey (AKU) the share of individuals who are business owners in the ages between

\footnotetext{
${ }^{1}$ The retirement age in Sweden is, during the sample years, 65 years and the elementary school is normally attended up to the age of 15 years.

${ }^{2} \mathrm{An}$ individual is defined as an owner of a limited company with few owners if the tax autorithy after an control finds an connection between the individual's and the company's tax declaration. Based on a comparison with business statistics (FRIDA) from Statistics Sweden it seems like a very large share of the business owners are controlled and hence captured by the definition.
} 
16 and 64 years is approximately 7.1 percent in year 2002. ${ }^{3}$ In AKU one is regarded as business owner if this is the main occupation of the individual. This would best correspond to our definition of self-employed and as we can see these figures are close. According to FRIDA, which is statistics of business owners from Statistics Sweden, the share of business owners in the ages 18-60 (based on total numbers and using the same types of businesses as in this paper) in year 2003 is 13,6 percent. As we can see, our definitions seems to capture the business owners and self-employed to a very large extent.

As discussed in the previous section the dependent variable will be transition into entrepreneurship instead of being entrepreneur. An individual is defined to enter entrepreneurship if he/she becomes a business owner in the subsequent period, that is, he/she is not defined as an entrepreneur in the current period but is defined as an entrepreneur in the following period. The share of individuals who becomes an entrepreneur in the sample is approximately 2.0 percent. And similar, an individual is defined to enter self-employment if the individual is neither self-employed nor business owner in the current period but self-employed in the following period. This share is approximately 0,9 percent in the sample.

\subsection{Explanatory variables}

\subsubsection{Wealth variables}

To investigate the role of liquidity constraints household wealth will be used in the main regressions. Household wealth is the summed up individual wealth for all the members of the household. The individual wealth is the sum of savings, checking accounts, bonds, stocks, individual taxable insurance, housing equity minus debt. For bonds, stocks and housing equity the market value is used. ${ }^{4} \mathrm{~A}$ household is defined as a family is defined for tax purposes, i.e., individuals who are married or have children together and in addition registered on the same address, and children under 18 registered on the same address. For convenience the wealth variables has been divided by 100,000 and, hence, all wealth variables are expressed in SEK 100,000.

A considerable share of the households (about 30 percent) has negative net wealth. This can partly be explained by the fact that the assets in some parts are underestimated. For instance, vehicles and assets invested abroad is only included for individuals with wealth larger than the tax limit of SEK 900,000. Moreover, the value of banking accounts are only reported if the interest rate exceeds SEK 100. Due to the low level of interest rates on banking accounts the value on the account has to be high to be reported. However, the most important explanation for the large share of individuals with negative wealth is probably debt incurred for higher education. In Sweden, higher education is very commonly financed by loans from the Swedish National Board of Student Aid (CSN).

The wealth variable will be specified in several different ways. We will use linear and polynomial wealth and also dummy variables for different levels of

\footnotetext{
${ }^{3}$ This figure is derived by dividing the number of individuals who in the survey stated that their main occupation was as a business owner divided by individuals who are employed, unemployed or not in the labor force.

${ }^{4}$ The market value is approximated for housing equity using assessed tax value and a purchase sum coefficient.
} 
wealth. As a robustness test we will also use individual wealth and gross household wealth as dependent variable.

\subsubsection{Other explanatory variables}

The logarithm of labor income will be included in the regressions. The effect of labor income can go in either direction. The labor income can have a positive effect on entrepreneurship since it can be seen as a measure of the quality of the worker. An individual with high experience and skills earns probably more and have better possibilities to find profitable business opportunities. However, the opposite effect on entrepreneurship have been emphasized by, for example, Evans and Leighton (1989) who find support for the disadvantage theory which views entrepreneurs as misfits. This is explained by the fact that low earning individuals have lower alternative costs entering entrepreneurship.

Another measure of misfit can be earlier experience of unemployment. The effect of unemployment is expected to be positive, which can be explained in the same way as labor income, lower alternative cost. It is also worth mentioning the existence of a special allowance in Sweden for unemployed individuals who wishes to start an own business. The purpose of this allowance is to help unemployed individuals with part of the costs that is associated with starting up a business. It is possible that this allowance increases the expected positive effect from unemployment. A dummy variable that is equal to one if the individual has received any unemployment benefits during the last year is included in the regressions.

Two variables for the family structure have been included, married and children. Children is a dummy variable indicating if there are any children under 18 years in the household. One possibility is that both variables are negatively correlated with entrepreneurship, which could be a consequence of the fact that individuals with a family is less willing to undertake a risky business venture. In general, however, the effect goes in the opposite direction. This could be explained by for example that a married individual will be more willing to take a risk because he/she can rely on getting financial support from his/her spouse (Parker 2004). An other possible reason for a positive relationship is that the spouse takes a bigger responsibility for household work so that the individual can concentrate on labor work outside the home. A different explanation could be found in underlying characteristics of married individuals. One can argue that beeing married requires some level of social skills and that these social skills are valuable when starting a business and potentially also finding financing.

As with previous variables, the effect of education can go in either direction. There are advance arguments for both negative and positive relationship with entrepreneurship. The evidence does, however, according to Parker (2004) point in the direction that education increases the probability to be or become an entrepreneur. This is according to, for example, Hedley and Shah (1986) explained by the fact that education increases the individuals human capital which enables him/her to find good business opportunities. In the context of liquidity constraints, a positive effect could reflect better opportunities to acquire a bank loan or other financing. One can imagine that for the financier education is seen as a signal of higher probability of refund. This view is supported by van der Sluis and van Praag (2004) who find that education decreases capital constraints. To account for education three dummy variables are included in 
the regressions. The dummy variables indicates if the individual has completed at least the indicated level, i.e., high school, college (2 years or more) or Ph. D..

The variable former entrepreneur is included to capture entrepreneurial traits. By including this variable the endogenity problem will be mitigated. Former entrepreneur is a dummy variable which is equal to one if the individual has been an entrepreneur, according to the definition used in the paper, under the last five years. The effect on transition into entrepreneurship is expected to be positive.

Other personal characteristics that have been included are gender, age and born abroad. In many previous studies the dummy variable male has been included and is found to be positively correlated with entrepreneurship. The effect of age is suspected to be ambiguous. Age is generally seen as an proxy for risk aversion, older persons are more risk averse, which would imply a negative effect. Older individuals does, however, in general have longer working experience and hence better possibilities to enhance good business opportunities. We suspect the relationship to be positive but diminishing. To capture this, both linear and squared age has been included in the regressions. The variable born abroad is included to control for differences in the propensity to become an entrepreneur between those born in Sweden and others. Discrimination in the lending market or labor market could cause a negative or correspondingly positive effect on entrepreneurship.

To account for aggregate time effects in the pooled sample year dummy variables are included.

In Table 1, mean values and standard deviations for business owners and non-business owners are presented.

On average, business owners have a larger initial wealth and labor income in the sample. The individuals are older and has to a larger extent a higher education. Moreover, business owners have to a larger extent been entrepreneurs before, unemployed the last year, has children, are married, males and born in Sweden.

\section{Estimation results: Net household wealth and transition into entrepreneurship}

To investigate the relationship between the transition into entrepreneurship and wealth we will use a probit model. Different specifications of wealth will be used to enable us to study the relationship carefully. In the base results we will first use different order polynomial specifications of wealth and then use a set of dummy variables. Moreover, a truncated sample is used to investigate the relationship relevant to this paper closer. After this we will examine how the results are affected if we separate the entrepreneurs into two groups depending on starting up costs for the businesses.

\subsection{Base results}

\subsubsection{Polynomial household wealth}

The standard approach in the literature has earlier been to include wealth linear or quadratic in the model. In a recent paper, Hurst and Lusardi (2004) use a 
Table 1: Summary Statistics for the whole sample

\begin{tabular}{lcc}
\hline \hline Variables & Non-Business Owners & Business Owners \\
\hline Household wealth & 5.6554 & 17.6599 \\
& $(27.2802)$ & $(81.3130)$ \\
Former entrepreneur (dummy variable) & .0668 & .8551 \\
& $(.2497)$ & $(.3520)$ \\
Born abroad (dummy variable) & .1607 & .1063 \\
& $(.3673)$ & $(.3082)$ \\
Log labor income & 10.8600 & 9.3888 \\
& $(3.5188)$ & $(4.9319)$ \\
Age & 38.4803 & 45.0667 \\
& $(12.2082)$ & $(9.7791)$ \\
High school (dummy variable) & .4972 & .4822 \\
& $(.5000)$ & $(.4997)$ \\
College (dummy variable) & .2805 & .2866 \\
& $(.4492)$ & $(.4522)$ \\
PhD (dummy variable) & .0064 & .0117 \\
& $(.0795)$ & $(.1076)$ \\
Unemployment (dummy variable) & .1317 & .0727 \\
& $(.3381)$ & $(.2597)$ \\
Children (dummy variable) & .1439 & .1937 \\
& $(.3510)$ & $(.3953)$ \\
Male (dummy variable) & .4930 & .6122 \\
& $(.5000)$ & $(.4873)$ \\
Married (dummy variable) & .3810 & .6111 \\
& $(.4856)$ & $(.4875)$ \\
\hline \hline
\end{tabular}

NOTE: Table entries are the means. Standard deviations are in parantheses. 
higher order polynomial in wealth. In this section we will follow this approach and use higher order polynomials in wealth. The idea with this is that the underlying relationship can be captured to a larger extent. By using a less restricted model we will be able to tell more about the relationship between entrepreneurship and wealth and its implications for liquidity constraints in Sweden.

We will start our analysis by using a first and second order polynomial as in earlier studies and in addition to this a sixth order polynomial in wealth. The sixth order polynomial is chosen among other high order polynomials because it is according to the log-likelihood ratio test the best suited. In Table 2, the parameter estimates and standard errors for wealth and the other explanatory variables from the first order polynomial wealth specification is presented.

Table 2: Probit estimates of transition into entrepreneurship: First order polynomial wealth

\begin{tabular}{lc}
\hline \hline Variable & Probit estimates \\
\hline Household wealth & $.0005^{* * *}$ \\
& $(.00005)$ \\
Former entrepreneur & $.3075^{* * *}$ \\
& $(.0098)$ \\
Born abroad & $.0314^{* * *}$ \\
& $(.0115)$ \\
Log labor income & $.0200^{* * *}$ \\
& $(.0013)$ \\
Age & $.0437^{* * *}$ \\
& $(.0029)$ \\
Age & $-.0005^{* * *}$ \\
& $(.00004)$ \\
High school & $.0551^{* * *}$ \\
& $(.0119)$ \\
College & $.1706^{* * *}$ \\
& $(.0127)$ \\
PhD & $.2346^{* * *}$ \\
& $(.0406)$ \\
Unemployment & $.0517^{* * *}$ \\
& $(.0127)$ \\
Children & $.0604^{* * *}$ \\
& $(.013)$ \\
Male & $.1467^{* * *}$ \\
& $(.009)$ \\
Married & $.0616^{* * *}$ \\
& $(.0102)$ \\
Year 2000 & $-.0324^{* * *}$ \\
Year 2001 & $(.0111)$ \\
& $.2502^{* * *}$ \\
Constant & $(.01)$ \\
& $-3.4185^{* * *}$ \\
& $(.0549)$ \\
\hline & $C$ Continued on next page \\
\end{tabular}


Table 2: continued

\begin{tabular}{lc}
\hline \hline Variable & Probit estimates \\
\hline & \\
Number of observations & 504,688 \\
McFaddens R-squared & 0.0376 \\
\hline \hline NOTE:All wealth variables are in SEK 100,000. Standard errors are in parentheses. \\
One star indicates 10 percent, two stars indicate 5 percent and three stars indicate \\
1 percent significance level of the estimate.
\end{tabular}

As can be seen in Table 2, wealth is significantly positive. The quantitative effect of wealth is, however, small. If we instead of studying the probit estimates look at the marginal effects of wealth we can see that an increase in wealth of SEK 100,000 around the mean of wealth increases the probability to enter entrepreneurship by only 0.0027 percent. ${ }^{5}$

As we expected, former experience of being entrepreneur raises the probability to enter entrepreneurship. The quantitative effect is relatively large, the probability to enter entrepreneurship increases with 1.7 percent if the individual has been entrepreneur before. This is a really high figure compared to the base probability of becoming entrepreneur which is 2.0 percent.

All variables for education are significant positive. Every discrete increase in education increases the probability to enter entrepreneurship. The positive effect could reflect that well educated individuals have better possibilities to find good business opportunities and possibly also that they face less severe liquidity constraints. Compared to wealth the marginal effect of education is large.

The result for unemployment gives support to the misfit theory. Experience of unemployment increases the probability to enter entrepreneurship. However, the result for labor income contradicts this result. A high labor income seems to increase the probability to enter entrepreneurship. This result could instead reflect the quality of the workers and that high income earners have better possibilities to find good business opportunities.

The regression indicates that being born abroad increases the probability to become an entrepreneur. As we could see in Table 1 business owners are to a smaller extent born abroad but the previous results suggest that a larger share of the individuals who are born abroad becomes business owners. This seemingly contradicting results suggests that the survivor time of the businesses of individuals who are born abroad are shorter compared to those of individuals born in Sweden.

As we expected the effect of age is positive but diminishing and males are to a larger extent becoming entrepreneurs than females. Having children and being married seems to have a positive effect on the probability to enter entrepreneurship. The positive effect from being married could be explained by the fact that a spouse can provide financial support and also take a bigger responsibility for domestic duties. And finally, the probability to enter entrepreneurship is highest in year 2001 and lowest in year 2000 .

\footnotetext{
${ }^{5}$ All reported marginal effects in this paper is computed by using the sample mean. Since the sample is large this will give the same answer as using average across individual marginal effects (Greene 2003). For the nonlinear variables the averages are pluged into the nonlinear functions instead of average the nonlinear function.
} 
Table 3: Probit estimates of transition into entrepreneurship: Second and Sixth order polynomial wealth

\begin{tabular}{|c|c|c|}
\hline Variables & Probit estimates & Probit estimates \\
\hline Household wealth & $\begin{array}{c}.0028^{* * *} \\
(.0001)\end{array}$ & $\begin{array}{c}.0073^{* * *} \\
(.0003)\end{array}$ \\
\hline$(\text { Household wealth) })^{2}$ & $\begin{array}{c}-1.06 \mathrm{e}-06^{* * *} \\
(8.41 \mathrm{e}-08)\end{array}$ & $\begin{array}{c}-9.00 \mathrm{e}-06^{* * *} \\
(2.00 \mathrm{e}-06)\end{array}$ \\
\hline$\left(\right.$ Household wealth) ${ }^{3}$ & & $\begin{array}{c}2.52 \mathrm{e}-08^{* * *} \\
(3.43 \mathrm{e}-09)\end{array}$ \\
\hline$\left(\right.$ Household wealth) ${ }^{4}$ & & $\begin{array}{c}-1.31 \mathrm{e}-11^{* * *} \\
(2.34 \mathrm{e}-12)\end{array}$ \\
\hline$(\text { Household wealth })^{5}$ & & $\begin{array}{c}3.13 \mathrm{e}-15^{* * *} \\
(6.70 \mathrm{e}-16)\end{array}$ \\
\hline$\left(\right.$ Household wealth) ${ }^{6}$ & & $\begin{array}{c}-2.78 \mathrm{e}-19^{* * *} \\
(6.72 \mathrm{e}-20)\end{array}$ \\
\hline Number of observations & 504,688 & 504,688 \\
\hline McFaddens R-squared & 0.0405 & 0.0434 \\
\hline
\end{tabular}

NOTE:All wealth variables are in SEK 100,000. Standard errors are in parentheses.

One star indicates 10 percent, two stars indicate 5 percent and three stars indicate

1 percent significance level of the estimate.

From here on we will only present and interpret the results for wealth. All explanatory variables are, however, included in all regressions. The results for the other variables are in large unaffected by the different specifications of wealth.

Table 3 presents the results from the second and sixth order polynomial wealth model.

As we can see, all wealth parameter estimates are highly significant. According to the second order specification the relationship is positive but diminishing, this could be an indication that there exists liquidity constraints that cease to bind. The total marginal effect of household wealth in the second order specification evaluated around the mean is 0.015 percent and in the sixth order specification it is 0.040 percent. ${ }^{6}$ If we compare this to the figure from the first order specification we can see that the marginal effect increases as the model gets less restricted.

A likelihood ratio test rejects the first and second order specification compared to the sixth order specification and the first order compared to the second order. To be able to interpret the results better the predicted probability to become an entrepreneur on initial household wealth is graphed in Figure 1. All other variables are held constant at their mean value.

As we can see the graphs of the different specification show very different features. There seems to be a lot of characteristics of the relationship that the first and second order specifications are not able to capture. However, the wealth distribution is characterized by very thin tails. For instance, there is only 14 individuals out of the more than 500,000 in the sample that have values of

\footnotetext{
${ }^{6}$ The total marginal effects in the paper are computed by differenting the response probability with respect to wealth. For instance, the total marginal effect for the second order polynomial specification is calculated using the equation $\delta P(y=1 \mid x) / \delta x_{w}=f(\bar{x} \hat{\beta})\left(\hat{\beta}_{w}+2 \hat{\beta}_{\left(w^{2}\right)} \bar{x}_{w}\right)$.
} 


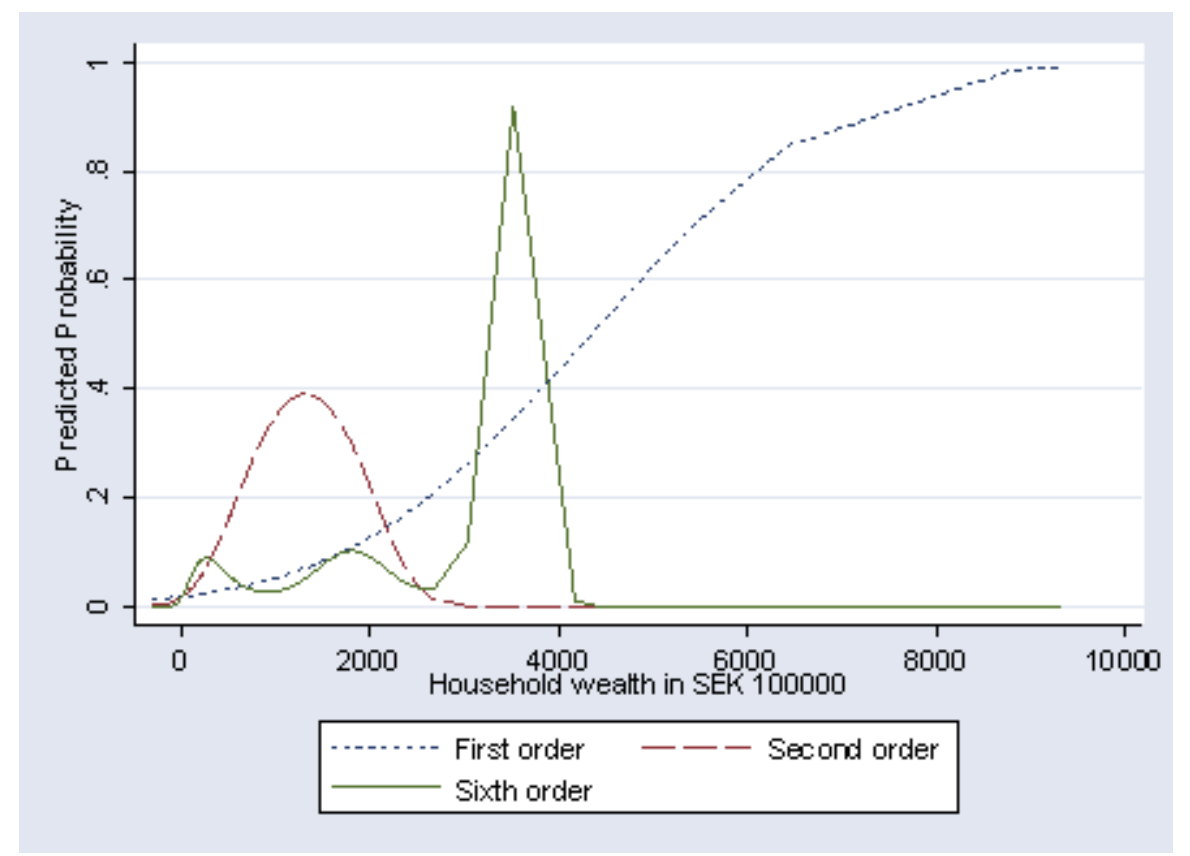

Figure 1: Predicted probability of transition into entrepreneurship: Polynomial wealth

wealth over SEK 200 millions and the 99:th percentile is about 7.5 millions. As discussed earlier, the most interesting and relevant relationship between transition into entrepreneurship and wealth in the context of liquidity constraints are found if we study the main part of the population closer. In Figure 2 the relationship between transition into entrepreneurship and wealth from Figure 1 is seen in more detail. The figure shows the relationship between one million in negative wealth and 8 millions in positive wealth which corresponds to a little bit more then the first and last percentile in the population.

In Figure 2 we can see that as we expected the marginal effect of wealth increases as we increase the order of the polynomials. Hurst and Lusardi (2004) finds that the impact of wealth decreases when they use a fifth order polynomial in wealth compared to the first order polynomial and from this they conclude that it is the very richest individuals that drive the positive relationship estimated with the first order polynomial. Our result points to the opposite, when using higher order polynomials the impact of wealth increases. Wealth seems to matter for the main part of the wealth distribution and hence it is not only the richest individuals that drive the positive relationship.

In the two following sections the relationship between wealth and entrepreneurship will be investigated even closer. First we will use dummy variables for wealth instead of polynomials and second a truncated sample will be used. 


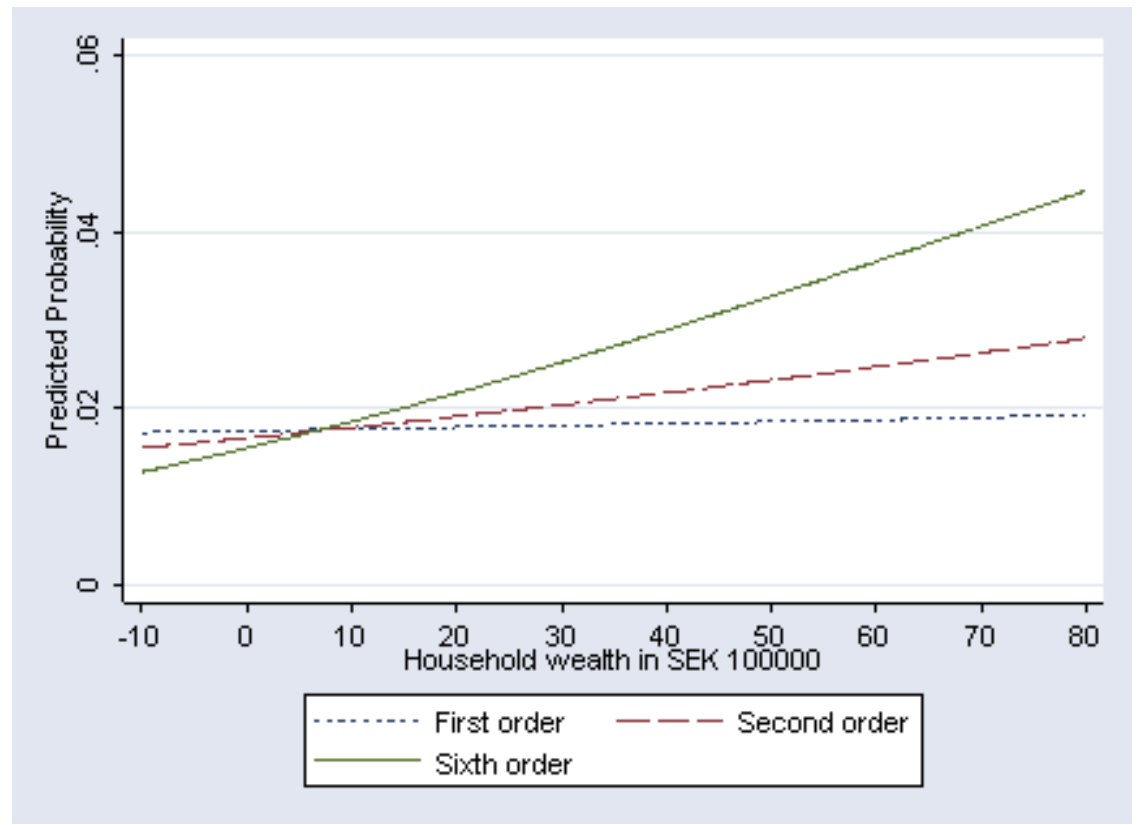

Figure 2: Predicted probability of transition into entrepreneurship: Polynomial wealth (close-up)

\subsubsection{Dummy variables for different wealth fractions}

The advantage with using dummy variables is that we do not put to much restrictions on the parametric form of wealth. In this section we will concentrate on the relationship between initial household wealth and transition into entrepreneurship in the interval between the first and last percentile of the wealth distribution. The first dummy variable is for individuals with wealth less than zero and the last is for individuals with more than seven millions in net household wealth. Between those values of wealth we have created a dummy variable for individuals representing the same wealth interval of SEK 500,000, hence, there is totally 16 dummy variables. After running the regression, we find that all wealth parameter estimates are significant at the one percent level (the probit estimates can be seen in Appendix A). The graph of the predicted probability from this regression together with the graph from the polynomial specifications can be seen in Figure 3 .

The sixth order polynomial specification seems to capture the relationship estimated by using dummy variables in the best way. This is what we expected based on the log-likelihood ratio test. It does, however, seems like all of the polynomial specifications underestimate the role of liquidity constraints in this interval. The marginal effect seems to be higher for the dummy variable specification. Moreover, there seems to be some features of the relationship that the polynomial specifications are not able to capture, but at least the sixth order specification provides us with a fairly good approximation of the relationship although the marginal effect is underestimated in some intervals.

The conclusion so far is that the marginal effect of an increase in wealth 


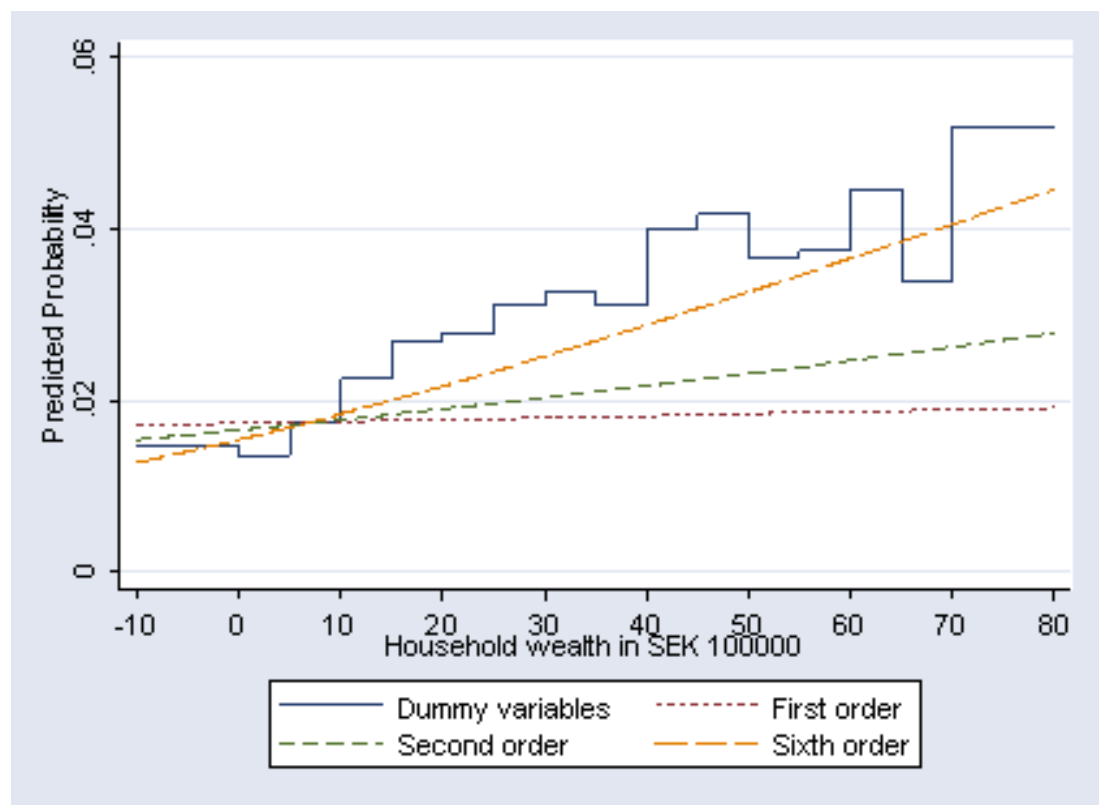

Figure 3: Predicted probability of transition into entrepreneurship: Dummy variables

increases as the models get less restricted with respect to wealth; when using a low order polynomial in wealth there is a risk that the importance of wealth is underestimated. This indicates that the role of liquidity constraints can have been underestimated rather than overestimated in earlier studies on Swedish data.

\subsubsection{Truncated sample}

In this section the sample will be truncated by not including observations in the top and bottom one percent of the wealth distribution. The idea with this is that we should be able to find out even more about the relationship between wealth and entrepreneurship that is relevant in terms of liquidity constraints. The interest of this paper is to investigating the role of liquidity constraints for largest share of the population and not for the outliers in the top and bottom of the distribution.

To find out which specification is best suited in this interval we rerun the regression with different orders of polynomial in wealth. By using log-likelihood ratio tests the sixth order polynomial specification is found to statistically dominate the other specifications. In addition to the sixth order polynomial the second order polynomial and dummy variable specification is used in this section. If we study the results from these regressions we find that all wealth parameter estimates are significant at the one percent level in the polynomial specifications and all except one in the dummy variable specification (the parameter estimates can be seen in Appendix B). If we study the marginal effects for wealth we can see that in the second order polynomial specification the total 


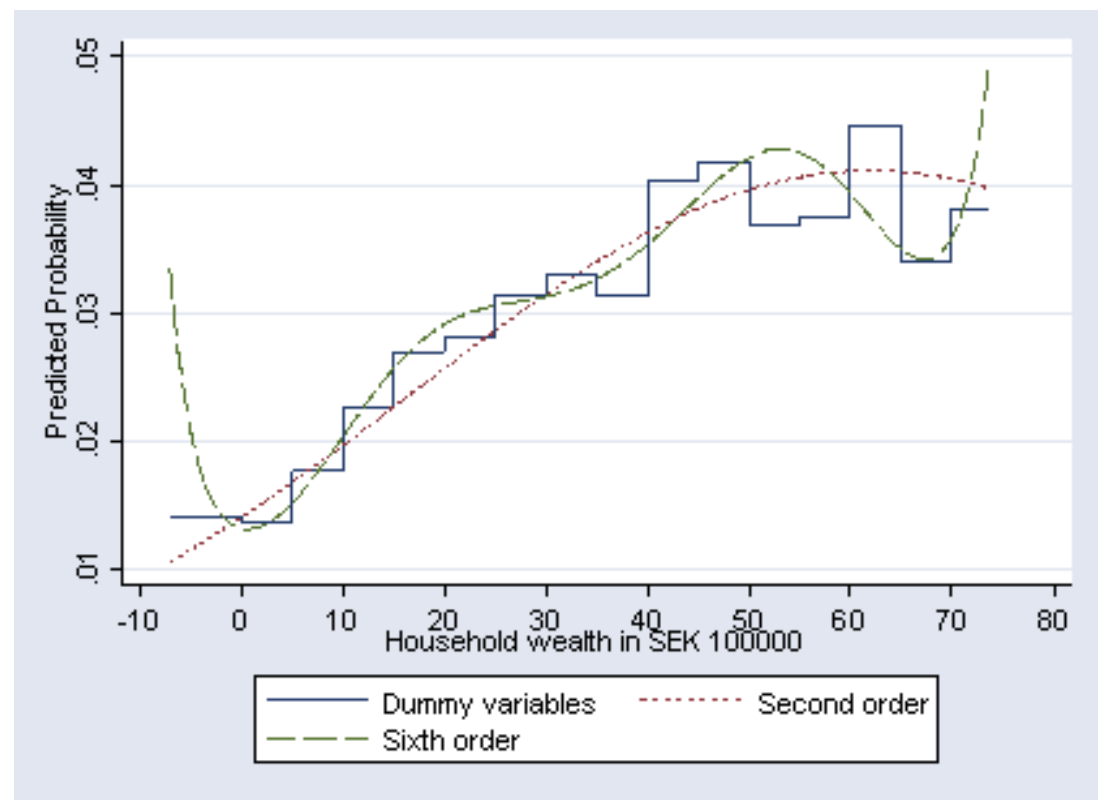

Figure 4: Predicted probability of transition into entrepreneurship: Truncated sample

marginal effect is 0.076 percent and in the sixth order specification 0.12 percent. Again we note that the marginal effect increases as the model gets less restricted. Moreover, compared to the model estimated on the whole sample the marginal effects in the truncated sample is significantly larger. It seems like the closer and more careful we look at the relationship between wealth and entrepreneurship the stronger the relationship becomes. The effect may still not seem very large, however, we have to keep in mind that the base probability to become an entrepreneur is 2.0 percent and that the probability increases (in the sixth order specification) with 0.12 percent for every SEK 100,000. To investigate the relationship and marginal effects over the whole intervall the different specifications are graphed together in Figure 4.

For positive wealth the sixth order polynomial specification follows the dummy variable specification close. The marginal effect is very large for positive wealth up to approximately 2 millions. After this the slope decreases somewhat and reaches new high levels around approximately 3.5 and 5 millions and 6.5 and 7.5 millions. For levels between 5 and 6.5 million the slope is negative. A possible explanation for the negative relationship for high levels of wealth is self-selection, i.e. individuals with large wealth do not need to work and hence choose not to work in neither an own firm nor as employed. However, as we can see the relationship is positive after 6.5 millions and hence this hypothesis is contradicted.

A striking feature of the sixth order polynomial specification is the large negative slope for negative values of wealth. This negative relationship can also be found if the first dummy variable is divided into more dummy variables. The explanation could possibly be found in different risk aversions. Among 
the individuals with high negative levels of wealth it is very possible that the riskaversion is smaller then among the rest of the population. In this group there may also be former entrepreneurs (more than five years ago) who has failed with their business. An other possible explanation is tax avoidance behavior. Individuals who have good knowledge in starting business can possibly also have good knowledge in avoiding tax and since the data is based on information for tax purposes this could explain the negative relationship. It is also possibly that there are some effect that we have not been able to control for from the fact that in this group there are a lot of newly examined undergraduate students. No matter of which explanation we believe in it is very reasonable to believe that this feature of the relationship is explained by some underlying characteristics of the individuals with negative wealth and not by the decreasing negative wealth itself. Or simply, that it reflects loans for businesses started in the subsequent year.

For positive wealth the main relationship seems to be pretty well captured by the second order specification. A relevant discussion in this context is overfitting. With the large sample size the degrees of freedom is no problem but maybe we capture features of the relationship that is very specific for this sample and when doing so we miss the interesting trend that is robust also outside the sample. Moreover, if we change the order of the polynomial the relationship changes mainly in the end and beginning of the interval. The main and for this paper most important feature of the graph is that the relationship between wealth and transition into entrepreneurship in large seems to be positive but diminishing for positive values of wealth. This feature of the graph could be explained by liquidity constraints that cease to bind and is well captured by the second order specification in the truncated sample

In the next section we will divide the entrepreneurs into two groups depending on starting up costs, by using this method we will get an indication whether the endogenity problem rather than the existence of liquidity constraints drive our results.

\subsection{Low and high starting capital}

The entrepreneurs in the sample will be divided into two groups, one for those entrepreneurs who start a low starting capital business and one for those who start a high starting capital business. The distinction between the groups is based on the same source as Hurst and Lusardi (2004), the 1987 NSSBF survey of small business finances, for closer description see Appendix C.1.

It is reasonable to believe, that if there are liquidity constraints then those entrepreneurs who start a high starting capital business will be depending on wealth, but for the entrepreneurs who start a low starting capital business wealth should not matter to the same extent. By using this method we will also avoid the endogenity problem. We have no reasons to believe that the endogenity problem should be more severe for entrepreneurs who starts a high starting capital business and hence a stronger relationship would really imply liquidity constraints.

A multinomial probit model (MNP) is used to estimate the relationship. By using the MNP model the independence from irrelevant alternatives (IIA) assumption is relaxed and because of this it is theoretically preferable compared to the multinomial logit model. The drawback of the MNP model is that it is very 


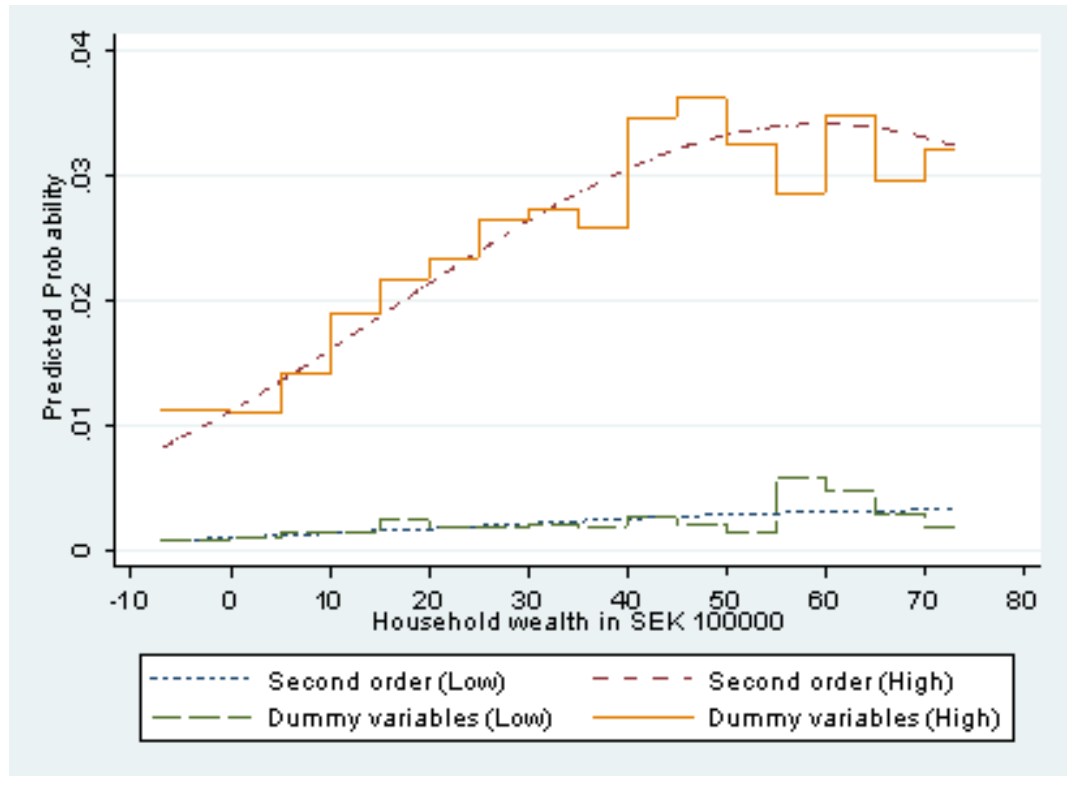

Figure 5: Predicted probability of transition into entrepreneurship: Low and high starting capital

computationally burdensome and that the identification is troublesome. However, in a model like the one we will use here with only three choices, satisfactory direct approximations in terms of speed and accuracy can be achieved without to much restrictions on the standard deviations and correlations (Greene 2003).

The choice of the individual is whether to start a high or low starting capital business or to stay in the current employment status. We are interested in how the relationship looks for the main part of the wealth distribution and not for the outliers in the two ends of the distribution and hence the sample is truncated in the top and bottom one percent. Based on the discussion of overfitting in previous section only the second order polynomial will be used. In addition to the second order polynomial a dummy variable specification is used. The dummy variables are used to get an idea of the relationship without putting to much parametric restrictions on it and the second order polynomial specification is used to capture the main features of the relationship.

The probit estimates from the regressions can be found in Appendix C.2. When comparing the significances of the wealth parameter estimates for high and low starting capital business owners we can see that the estimates for the low starting capital is somewhat less significant. However, in both the specifications the large majority of the estimates are at least significant at the five percent level. The graph from the regressions can be seen in Figure 5 .

As we can see, although the relationship between wealth and starting a low starting capital business is significant, the effect is very small. The general trend is clear, the marginal effect of wealth seems to be smaller for entrepreneurs who start a low starting capital business compared to high starting capital business. For instance, in the second order polynomial specification the total 
marginal effect of an increase in wealth with SEK 100,000 around the mean is for the low starting capital 0.00018 percent compared to the considerable larger marginal effect for high starting capital 0.012 percent. However, these figures are not directly comparable because the base probability to start a low starting capital business is much lower than the probability to start a high starting capital business. It follows that the index function is much smaller for the low starting capital option which implies smaller marginal effects. If we divide the marginal effects with the corresponding base probabilities the figures are comparable. After doing this divisions we find that the relative marginal effect for low starting capital is 0.11 percent and for high starting capital it is 0.75 percent. Hence, the conclusion remains: the marginal impact of wealth is considerable larger for entrepreneurs who start a high starting capital business compared to those who start a low starting capital business. To sum up, we have found important differences between starting a high and a low starting capital business and this result suggests that wealth mainly matters for entrepreneurs who have started a high starting capital business. This indicates the existence of liquidity constraints and that the positive relationship estimated in previous sections really are driven by liquidity constraints and not by the endogenity problem.

\section{Robustness analysis}

In this section the robustness of previous results will be tested. To do this we use a number of alternative specifications. We use both alternative measures of wealth and an alternative definition of entrepreneurship and in addition to this we will study the three years separately.

Once again the sample is truncated in the top and bottom one percent of the different wealth distributions and a dummy variable and second order polynomial specification in wealth is used.

\subsection{Alternative specifications of wealth and entrepreneur- ship}

Instead of net household wealth, net individual wealth and gross household wealth will be used and as an alternative definition of entrepreneurship we will use self-employment. The results are graphed and given in Figure $6{ }^{7}$

The second order polynomial seems to capture the relationship well except for gross household wealth where the level is to high. As we can see, the features of the graphs are very similar to the original specification. For all alternative specifications the relationship between wealth and entrepreneurship seems to be positive but diminishing which can be an indication of liquidity constraints that cease to bind. Hence, the result that there exists liquidity constraints on the Swedish market is confirmed by looking at alternative specifications in wealth and entrepreneurship. In the next section we will examine if the result is robust over time and business cycles.

\footnotetext{
${ }^{7}$ The estimation results are available on request.
} 


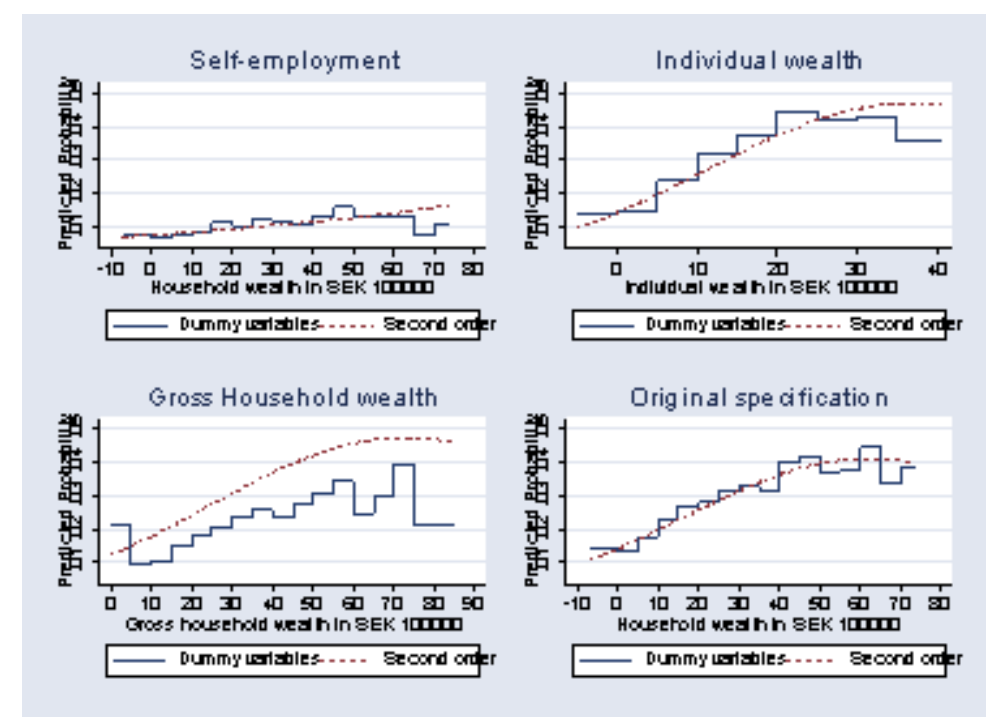

Figure 6: Predicted probability of transition into entrepreneurship: Alternative specifications of wealth and entrepreneurship

\subsection{Subsamples depending on year}

The sample will be divided into three subsample depending on year. By doing this division we will see if the relationship is robust over time and over business cycles. During the period investigated Sweden experienced both a boom and a bust, in the 1999 and 2000 the economic climate in Sweden was positive and the country experienced a boom, in the beginning of 2001 the climate changed and the economy turned into a bust. One can imagine several different effects from different economic situations in the economy. The relationship between a bust and liquidity constraints could possibly be less severe due to that the demand for capital probably is smaller. However, it is also easy to imagine the opposite effect. In times of pessimism and negative development the financing institutes can become more negative towards accepting loans and hence the liquidity constraints increases. Moreover, private equity can be expected to decline as a result of assets loosing their value. The resulting graphs from the regressions can be seen in Figure 7 .

In Figure 7 we can see that for all years the relationship between wealth and transition into entrepreneurship is positive and diminishing as for the pooled sample. However, the relationship between wealth and transition into entrepreneurship is much stronger for the last year in the sample compared to the other. As we expected, the level is higher in year 2001 but as we can see so are the marginal effects. If we do a more formal comparison and compare the marginal effects around the mean then the idea from the graphs is confirmed. The total marginal effect evaluated around the mean is in year 19990.048 percent, in year 20000.044 percent and in year 20010.14 percent. As discussed before it would be misleading to compare these figures directly. If we divide each marginal effect with the corresponding base probability of becoming entrepreneur we get the relative marginal effects. For year 1999 this is 3.0 percent, for year $20002.9 \%$ 


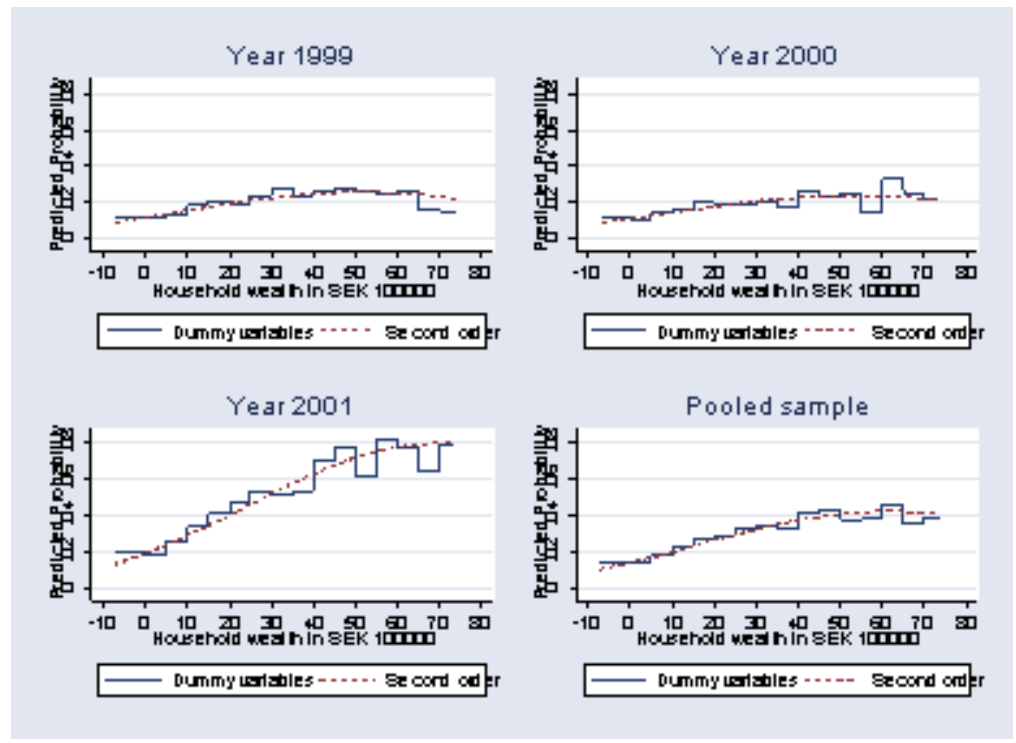

Figure 7: Predicted probability of transition into entrepreneurship: Subsamples depending on year

and for year 2001 it is $4.9 \%$. Thus, we can confirm that the marginal effect from wealth is largest in year 2001.

As said before Sweden experienced a falling business cycle during 2001 and this seems to have resulted in more severe liquidity constraints facing potential entrepreneurs in 2002. In the introduction the link between the lack of venture capital and liquidity constraints where discussed. An interesting comparison can be made based on the previous results and the development of the Swedish private equity and venture capital industry. According to EVCA (2004) the Swedish venture capital market experienced a extraordinary growth during the late 1990's and through to year 2000. After this a significantly lower activity followed in 2001 and 2002. To draw any extensive conclusion out of this would be too rash, but it is an interesting and plausible conclusion that the stronger relationship between wealth and transition into entrepreneurship in year 2001 can be explained by the decline in venture capital. This is yet an other indication that the positive correlation is driven by liquidity constraints and that a major cause for these liquidity constraints are the lack of venture capital in early development phases in Sweden.

\section{Conclusion}

In a recent paper, Hurst and Lusardi (2004) find that the propensity to become entrepreneur is nonlinear in wealth and that the relationship between wealth and entrepreneurship is flat over the largest part of the wealth distribution in the United States. They find that it is only in the very top of the distribution that the relationship is positive and that the linear positive relationship earlier found is driven by these individuals. 
In this paper we have used similar methods to investigate the relationship between wealth and entrepreneurship on Swedish data. Thanks to the large sample size we are able to extend the analysis by using fine definitions of the dummy variables. In accordance with Hurst and Lusardi (2004) finding, we find that wealth is not a first order polynomial. However, we are not able to confirm the view that wealth matters only for individuals in the very top of the wealth distribution. Instead, we find that the relationship between wealth and entrepreneurship is positive and diminishing. The positive and diminishing relationship can be explained by liquidity constraints that cease to bind. We also find that the impact of wealth increases as we use less restricted models with respect to wealth and a truncated sample, this indicates that the relationship between wealth and entrepreneurship possibly has been underestimated in earlier studies on swedish data. In addition, we find that wealth mainly matters for entrepreneurs who start a high starting capital business, this is a further indication of the existence of liquidity constraints in Sweden. By using alternative definitions of entrepreneurship and wealth and different sample periods we have found that our main results are robust.

The evidence from our data seems to agree that the main share of new potential entrepreneurs in Sweden are actually liquidity constrained. However, the problem of endogenity may remain. The positive relationship between wealth and entrepreneurship could possibly be explained by common traits that both render wealth and that make the individual more prone to enter entrepreneurship. The question is only how severe this problem is. There are two reasons that makes us believe that the endogenity problem is not that severe in this sample. First, as discussed before, part of the endogenity that is still present after using transition into entrepreneurship is handled by including former entrepreneur as explanatory variable. Second, the result that the relationship between entrepreneurship and wealth is stronger for high starting capital businesses indicates that the relationship is driven by liquidity constraints and not by common traits.

The result of the paper is in accordance with our expectations. Based on the described situation with lack of capital, in particular venture capital in the starting up phase, in Sweden and the rest of Europe we are not surprised that the results implies that there exists liquidity constraints on the Swedish market and based on a comparison with the results of Hurst and Lusardi (2004) that the constraints seems to be more severe in Sweden than in the United States. In a recent paper Holtz-Eakin and Rosen (2005) analyze U.S. and German micro data and find that German workers face more severe liquidity constraints than their counterparts in the United States. The result of this paper is consistent with this finding and support the view that European entrepreneurship are hindered by lack of institutions who provide starting-up capital. The explanation of the lack of venture capitalists in European countries including Sweden is in business literature relatively well debated. For instance, Braunerhjelm (1999) argues that the structure of taxes in Sweden discourage venture capitalists by for example putting a higher tax burden on venture capitalists than on other investors. Baygan (2003) reviews the Swedish venture capital policies and suggests that necessary steps for Sweden include removing quantitative restrictions on venture investments by financial institutions, lowering tax rates, and restructing equity programmes.

This paper contributes with evidence that there are liquidity constraints or 
lack of starting up capital in Sweden and that there are possibly more severe constraints in Sweden (and Europe) than in the United States. The reasons and consequences of this potential lack of capital and gap between the United States and Europe is an interesting and important topic for further research in the field. 


\section{References}

Baygan, G.: 2003, Venture capital policy review: Sweden, Workingpaper 11, OECD Directorate for Science, Technology and Industry, http://www.oecd.org/sti/working-papers.

Bottazzi, L. and da Rin, M.: 2003, Financing entrepreneurial firms in europe: Facts, issues, and research agenda, Working Paper 958, CESifo.

Braunerhjelm, P.: 1999, Venture capital, mångfald och tillväxt, Ekonomisk debatt 27(4), 213-221.

Evans, D. S. and Jovanovic, B.: 1989, An estimated model of entrepreneurial choice under liquidity constraints, The Journal of Political Economy 97(4), 808-827.

Evans, D. S. and Leighton, L. S.: 1989, Some empirical aspects of entrepreneurship, The American Economic Review 79(3), 519-535.

EVCA: 2004, EVCA yearbook 2004, European Private Equity and Venture Capital Association.

Giannetti, M. and Simonov, A.: 2004, On the determinants of entrepreneurial activity: Social norms, economic environment and individual characteristics, Swedish Economic Policy Review 11(2), 271-313.

Greene, W. H.: 2003, Econometric Analysis, 5 edn, Prentice Hall.

Hedley, R. and Shah, A.: 1986, An empirical analysis of self-employment in the U.K., Journal of Applied Econometrics 1(1), 95-108.

Holtz-Eakin, D. and Rosen, H. S.: 2005, Cash constraints and business startups: Deutshmarks versus dollars, Contributions to Economic Analysis \& Policy 4(1).

Hurst, E. and Lusardi, A.: 2004, Liquidity constraints, household wealth and entrepreneurship, Journal of Political Economy 112(2), 319-347.

Lindh, T. and Ohlsson, H.: 1996, Self-employment and windfall gains: Evidence from sweden, The Economic Journal 106(439), 1515-1526.

Lindh, T. and Ohlsson, H.: 1998, Self-employment and wealth inequality, Review of Income and Wealth 44(1), 25-41.

Lucas, R. E.: 1978, On the size distribution of business firms, Bell Journal of Economics 9(2), 508-523.

Parker, S. C.: 2004, The Economics of Self-employment and Entrepreneurship, Cambridge University Press.

van der Sluis, J. and van Praag, M.: 2004, Economic returns to education for entrepreneurs: The development of a neglected child in the family of economics of education, Swedish Economic Policy Review 11(2), 183-225. 


\section{Appendix:}

\section{A Estimation results for the dummy variable specification}

Table 4: Probit estimates of transition into entrepreneurship: Dummy variables

\begin{tabular}{|c|c|}
\hline Wealth dummy variables & Probit estimates \\
\hline$\overline{\mathrm{wd}} 2$ & $\begin{array}{c}-.0293^{* * *} \\
(.0112)\end{array}$ \\
\hline wd 3 & $\begin{array}{c}.0708^{* * *} \\
(.0142)\end{array}$ \\
\hline wd 4 & $\begin{array}{c}.1747^{* * *} \\
(.0167)\end{array}$ \\
\hline wd 5 & $\begin{array}{c}.2484^{* * *} \\
(.0196)\end{array}$ \\
\hline wd 6 & $\begin{array}{c}.2664^{* * *} \\
(.0233)\end{array}$ \\
\hline wd 7 & $\begin{array}{c}.3153^{* * *} \\
(.0268)\end{array}$ \\
\hline wd 8 & $\begin{array}{c}.3367^{* * *} \\
(.0313)\end{array}$ \\
\hline wd 9 & $\begin{array}{c}.3142^{* * *} \\
(.0371)\end{array}$ \\
\hline wd 10 & $\begin{array}{c}.4296^{* * *} \\
(.0395)\end{array}$ \\
\hline wd 11 & $\begin{array}{c}.4469^{* * *} \\
(.0456)\end{array}$ \\
\hline wd 12 & $\begin{array}{c}.3882^{* * *} \\
(.0537)\end{array}$ \\
\hline wd 13 & $\begin{array}{c}.397^{* * *} \\
(.0599)\end{array}$ \\
\hline wd 14 & $\begin{array}{c}.4789^{* * *} \\
(.0658)\end{array}$ \\
\hline wd 15 & $\begin{array}{c}.3519^{* * * *} \\
(.0805)\end{array}$ \\
\hline wd 16 & $\begin{array}{c}.5516^{* * *} \\
(.0289)\end{array}$ \\
\hline Number of observations & 504,688 \\
\hline McFaddens R-squared & 0.0466 \\
\hline
\end{tabular}

NOTE:All wealth variables are in SEK 100,000. Standard errors are in parentheses. One star indicates 10 percent, two stars indicate 5 percent and three stars indicate 1 percent significance level of the estimate. wd stands for wealth dummy variable, wd 2 corresponds to the second intervall, wd 3 to the third intervall etc. 


\section{B Estimation results for the truncated sample}

Table 5: Probit estimates of transition into entrepreneurship: Truncated sample

\begin{tabular}{|c|c|c|c|}
\hline \multirow{2}{*}{ Variable } & \multicolumn{3}{|c|}{ Probit estimates } \\
\hline & Second order & Sixth order & Dummy variables \\
\hline Household wealth & $\begin{array}{c}.0148^{* * *} \\
(.0008)\end{array}$ & $\begin{array}{c}-.0052^{* * *} \\
(.0019)\end{array}$ & \\
\hline$(\text { Household wealth })^{2}$ & $\begin{array}{c}-.0001^{* * *} \\
(.00002)\end{array}$ & $\begin{array}{l}.0046^{* * * *} \\
(.0004)\end{array}$ & \\
\hline$\left(\right.$ Household wealth) ${ }^{3}$ & & $\begin{array}{c}-.0002^{* * *} \\
(.00003)\end{array}$ & \\
\hline$\left(\right.$ Household wealth) ${ }^{4}$ & & $\begin{array}{c}9.00 \mathrm{e}-06^{* * *} \\
(1.00 \mathrm{e}-06)\end{array}$ & \\
\hline$\left(\right.$ Household wealth) ${ }^{5}$ & & $\begin{array}{c}-1.13 \mathrm{e}-07^{* * *} \\
(1.71 \mathrm{e}-08)\end{array}$ & \\
\hline$\left(\right.$ Household wealth) ${ }^{6}$ & & $\begin{array}{c}5.37 \mathrm{e}-10^{* * *} \\
(9.45 \mathrm{e}-11)\end{array}$ & \\
\hline wd 2 & & & $\begin{array}{r}-.0117 \\
(.0114)\end{array}$ \\
\hline wd 3 & & & $\begin{array}{c}.0903^{* * *} \\
(.0144)\end{array}$ \\
\hline wd 4 & & & $\begin{array}{c}.1947^{* * *} \\
(.0169)\end{array}$ \\
\hline wd 5 & & & $\begin{array}{c}.2686^{* * *} \\
(.0198)\end{array}$ \\
\hline wd 6 & & & $\begin{array}{c}.2864^{* * *} \\
(.0235)\end{array}$ \\
\hline wd 7 & & & $\begin{array}{c}.3350^{* * * *} \\
(.0269)\end{array}$ \\
\hline wd 8 & & & $\begin{array}{c}.3563^{* * *} \\
(.0314)\end{array}$ \\
\hline wd 9 & & & $\begin{array}{c}.3340^{* * *} \\
(.0372)\end{array}$ \\
\hline wd 10 & & & $\begin{array}{c}.4489^{* * *} \\
(.0396)\end{array}$ \\
\hline wd 11 & & & $\begin{array}{c}.4661^{* * *} \\
(.0457)\end{array}$ \\
\hline wd 12 & & & $\begin{array}{c}.4074^{* * *} \\
(.0538)\end{array}$ \\
\hline wd 13 & & & $\begin{array}{c}.4156^{* * *} \\
(.0599)\end{array}$ \\
\hline wd 14 & & & $\begin{array}{c}.4977^{* * *} \\
(.0658)\end{array}$ \\
\hline wd 15 & & & $\begin{array}{c}.3708^{* * *} \\
(.0805)\end{array}$ \\
\hline
\end{tabular}


Table 5: continued

\begin{tabular}{lccc}
\hline \hline Variable & \multicolumn{2}{c}{ Probit estimates } \\
& Second order & Sixth order & Dummy variables \\
\hline wd 16 & & & $.4237^{* * *}$ \\
& & & $(.099)$ \\
& & & \\
Number of observations & 494,596 & 494,596 & 494,596 \\
McFaddens R-squared & 0.0437 & 0.0454 & 0.0446 \\
\hline
\end{tabular}

NOTE:All wealth variables are in SEK 100,000. Standard errors are in parentheses. One star indicates 10 percent, two stars indicate 5 percent and three stars indicate 1 percent significance level of the estimate. wd stands for wealth dummy variable, wd 2 corresponds to the second intervall, wd 3 to the third intervall etc.

\section{Low and high starting capital}

\section{C.1 Division into low and high starting capital}

The division into low and high starting capital industry is based on the 1987 National Survey of Small Business Finances. The target population of the survey is nonfinancial, nonprofessional and nonfarm businesses with fewer then 500 employees. By using the classification by economic activity according to SNI92 we have divide the businesses into the different industries in the NSSBF. In addition to this, the forest industry, agriculture, hunting and fishing is supposed to be high starting capital businesses. Individuals with businesses that have missing values for the industry code has been deleted from the sample. In Table 6 the different industries and their SNI92-code is presented. The SNI92-code is in parentheses and corresponds to the main group and/or the specific industrycode.

Table 6: Division into high and low starting buisnesses

\begin{tabular}{|l|l|}
\hline & Type of Industry (SNI92-code) \\
\hline Low starting capital: & $\begin{array}{l}\text { construction (F) } \\
\text { services }(\mathrm{O}: 91 ; 93, \mathrm{P})\end{array}$ \\
\hline High starting capital: & $\begin{array}{l}\text { Transportation, communication an public utilities } \\
\text { (E, I, L, M, N, O:90;92) } \\
\text { Mining (C) } \\
\text { Finance, insurance and real estate (J, K) } \\
\text { Manufacturing (D) } \\
\text { Wholesale trade } \\
\text { Retail trade }(\mathrm{G}, \mathrm{H}) \\
\text { Forrest industry, agriculture and hunting (A) } \\
\text { Fishing (B) }\end{array}$ \\
\hline
\end{tabular}




\section{C.2 Estimation results}

Table 7: Probit estimates of transition into entrepreneurship: High and low starting capital

\begin{tabular}{|c|c|c|c|c|}
\hline \multirow[b]{2}{*}{ Variables } & \multicolumn{2}{|c|}{ High starting capital } & \multicolumn{2}{|c|}{ Low starting capital } \\
\hline & $\begin{array}{c}\text { Second } \\
\text { order }\end{array}$ & $\begin{array}{c}\text { Dummy } \\
\text { variables }\end{array}$ & $\begin{array}{c}\text { Second } \\
\text { order }\end{array}$ & $\begin{array}{c}\text { Dummy } \\
\text { variables }\end{array}$ \\
\hline Household wealth & $\begin{array}{c}.0220^{* * *} \\
(.0012)\end{array}$ & & $\begin{array}{c}.0163^{* * *} \\
(.0030)\end{array}$ & \\
\hline$\left(\right.$ Household wealth) ${ }^{2}$ & $\begin{array}{c}-.00022^{* * *} \\
(2.48 \mathrm{e}-05)\end{array}$ & & $\begin{array}{l}-.0001^{*} \\
(5.96 \mathrm{e}-05)\end{array}$ & \\
\hline wd 2 & & $\begin{array}{l}-.0132 \\
(.0174)\end{array}$ & & $\begin{array}{l}.0492 \\
(.0411)\end{array}$ \\
\hline wd 3 & & $\begin{array}{c}.1263^{* * *} \\
(.0217)\end{array}$ & & $\begin{array}{c}.2164^{* * *} \\
(.0504)\end{array}$ \\
\hline wd 4 & & $\begin{array}{c}.2927^{* * *} \\
(.0252)\end{array}$ & & $\begin{array}{c}.1917^{* * *} \\
(.0655)\end{array}$ \\
\hline wd 5 & & $\begin{array}{c}.3760^{* * *} \\
(.0297)\end{array}$ & & $\begin{array}{c}.4660^{* * *} \\
(.0676)\end{array}$ \\
\hline wd 6 & & $\begin{array}{c}.4195^{* * *} \\
(.0348)\end{array}$ & & $\begin{array}{c}.3476^{* * *} \\
(.0883)\end{array}$ \\
\hline wd 7 & & $\begin{array}{c}.4937^{* * *} \\
(.0397)\end{array}$ & & $\begin{array}{c}.3528^{* * *} \\
(.1049)\end{array}$ \\
\hline wd 8 & & $\begin{array}{c}.5145^{* * *} \\
(.0466)\end{array}$ & & $\begin{array}{c}.4094^{* * *} \\
(.1187)\end{array}$ \\
\hline wd 9 & & $\begin{array}{c}.4773^{* * *} \\
(.0553)\end{array}$ & & $\begin{array}{c}.3682^{* *} \\
(.1434)\end{array}$ \\
\hline wd 10 & & $\begin{array}{c}.6637^{* * *} \\
(.0580)\end{array}$ & & $\begin{array}{c}.5338^{* *} \\
(.1468)\end{array}$ \\
\hline wd 11 & & $\begin{array}{c}.6888^{* * *} \\
(.0670)\end{array}$ & & $\begin{array}{c}.4231^{* * *} \\
(.1873)\end{array}$ \\
\hline wd 12 & & $\begin{array}{c}.6206^{* * *} \\
(.0783)\end{array}$ & & $\begin{array}{l}.2858 \\
(.2416)\end{array}$ \\
\hline wd 13 & & $\begin{array}{c}.5532 \text { *** } \\
(.0904)\end{array}$ & & $\begin{array}{c}.8856^{* * *} \\
(.1672)\end{array}$ \\
\hline wd 14 & & $\begin{array}{c}.6726^{* * *} \\
(.0991)\end{array}$ & & $\begin{array}{c}.8098^{* * *} \\
(.2040)\end{array}$ \\
\hline wd 15 & & $\begin{array}{c}.5654^{* * *} \\
(.1174)\end{array}$ & & $\begin{array}{c}.5610^{* *} \\
(.2744)\end{array}$ \\
\hline wd 16 & & $\begin{array}{c}.6129^{* * *} \\
(.1505)\end{array}$ & & $\begin{array}{l}.3821 \\
(.4324)\end{array}$ \\
\hline Number of obs. & 493,805 & 493,805 & 493,805 & 493,805 \\
\hline
\end{tabular}

NOTE:All wealth variables are in SEK 100,000. Standard errors are in parentheses. One star indicates 10 percent, two stars indicate 5 percent and three stars indicate 1 percent significance level of the estimate. wd stands for wealth dummy variable, wd 2 corresponds to the second intervall, wd 3 to the third intervall etc. 
WORKING PAPERS*

Editor: Nils Gottfries

2004:13 Pär Österholm, Estimating the Relationship between Age Structure and GDP in the OECD Using Panel Cointegration Methods. 32 pp.

2004:14 Per-Anders Edin and Magnus Gustavsson, Time Out of Work and Skill Depreciation. $29 \mathrm{pp}$.

2004:15 Sören Blomquist and Luca Micheletto, Redistribution, In-Kind Transfers and Matching Grants when the Federal Government Lacks Information on Local Costs. 34 pp.

2004:16 Iida Häkkinen, Do University Entrance Exams Predict Academic Achievement? 38 pp.

2004:17 Mikael Carlsson, Investment and Uncertainty: A Theory-Based Empirical Approach. 27 pp.

2004:18 N. Anders Klevmarken, Towards an Applicable True Cost-of-Living Index that Incorporates Housing. 8 pp.

2004:19 Matz Dahlberg and Karin Edmark, Is there a "Race-to-the-Bottom" in the Setting of Welfare Benefit Levels? Evidence from a Policy Intervention. $34 \mathrm{pp}$.

2004:20 Pär Holmberg, Unique Supply Function Equilibrium with Capacity Constraints. $31 \mathrm{pp}$.

2005:1 Mikael Bengtsson, Niclas Berggren and Henrik Jordahl, Trust and Growth in the 1990s - A Robustness Analysis. 30 pp.

2005:2 Niclas Berggren and Henrik Jordahl, Free to Trust? Economic Freedom and Social Capital. 31 pp.

2005:3 Matz Dahlberg and Eva Mörk, Public Employment and the Double Role of Bureaucrats. 26 pp.

2005:4 Matz Dahlberg and Douglas Lundin, Antidepressants and the Suicide Rate: Is There Really a Connection? 31 pp.

2005:5 Maria Vredin Johansson, Tobias Heldt and Per Johansson, Latent Variables in a Travel Mode Choice Model: Attitudinal and Behavioural Indicator Variables. 31 pp.

2005:6 Katarina Nordblom and Henry Ohlsson, Tax Avoidance and Intra-Family Transfers. 25 pp.

\footnotetext{
* A list of papers in this series from earlier years will be sent on request by the department.
} 
2005:7 Sören Blomquist and Luca Micheletto, Optimal Redistributive Taxation when Government’s and Agents’ Preferences Differ. 22 pp.

2005:8 Ruth-Aïda Nahum, Income Inequality and Growth: A Panel Study of Swedish Counties 1960-2000. 39 pp.

2005:9 Olof Åslund and Peter Fredriksson, Ethnic Enclaves and Welfare Cultures Quasi-experimental Evidence. 37 pp.

2005:10 Annika Alexius and Erik Post, Exchange Rates and Asymmetric Shocks in Small Open Economies. 31 pp.

2005:11 Martin Ågren, Myopic Loss Aversion, the Equity Premium Puzzle, and GARCH. 34 pp.

2005:12 Pär Holmberg, Numerical Calculation of an Asymmetric Supply Function Equilibrium with Capacity Constraints. 18 pp.

2005:13 Jovan Zamac, Winners and Losers from a Demographic Shock under Different Intergenerational Transfer Schemes. 44 pp.

2005:14 Peter Welz and Pär Österholm, Interest Rate Smoothing versus Serially Correlated Errors in Taylor Rules: Testing the Tests. 29 pp.

2005:15 Helge Bennmarker, Kenneth Carling and Bertil Holmlund, Do Benefit Hikes Damage Job Finding? Evidence from Swedish Unemployment Insurance Reforms. 37 pp.

2005:16 Pär Holmberg, Asymmetric Supply Function Equilibrium with Constant Marginal Costs. 27 pp.

2005:17 Pär Holmberg, Comparing Supply Function Equilibria of Pay-as-Bid and Uniform-Price Auctions. 25 pp.

2005:18 Anders Forslund, Nils Gottfries and Andreas Westermark, Real and Nominal Wage Adjustment in Open Economies. 49 pp.

2005:19 Lennart Berg and Tommy Berger, The Q Theory and the Swedish Housing Market - An Empirical Test. 16 pp.

2005:20 Matz Dahlberg and Magnus Gustavsson, Inequality and Crime: Separating the Effects of Permanent and Transitory Income. 27 pp.

2005:21 Jenny Nykvist, Entrepreneurship and Liquidity Constraints: Evidence from Sweden. 29 pp.

See also working papers published by the Office of Labour Market Policy Evaluation http://www.ifau.se/ 